\title{
Musculoskeletal disorders amongst workers of glass manufacturing unit of Western Uttar Pradesh
}

\author{
Sonia Tewari* \\ Department of Family Resource Management, College of Home Science, GB Pant \\ University of Agriculture and Technology, Pantnagar-263145 (Uttarakhand), India \\ Deepa Vinay \\ Department of Family Resource Management, College of Home Science, GB Pant \\ University of Agriculture and Technology, Pantnagar-263145 (Uttarakhand), India \\ *Corresponding author. E-mail: soniatewari38334@gmail.com
}

\begin{abstract}
Glass manufacturing process is a very tiresome job and the working near by the furnace makes tasks more difficult for workers as the environment is very hot. Apart from working in a hot environment various awkward postures was adopted while performing various activities which are monotonous and repetitive in nature and resulted in discomfort of various body parts. The workers perform various task and activities in extremely hot environment for at least 6 hours a day. In order to identify the various discomfort body regions, a total of 120 samples were selected conveniently from one of the glass manufacturing unit of Western UP for body mapping exercise. The study findings revealed that $37.50 \%$ respondent reported pain in their wrist followed by lower back $(30.82 \%)$ and knee pain $(27.50 \%$.) The other discomfort regions in body were neck, shoulder, upper back, elbow/forearm, thigh and ankle and foot. The problem in the wrist were more prominent among blowers $(59.46 \%)$ followed by ball makers $(50.00 \%)$.While problem of lower back found to be more common among blowers (45.95\%) and mold closers $(26.92 \%)$ and helpers i.e. $30.43 \%$. Relationship between task performed and the level of discomfort was found to be significant (at 5\%) in neck, lower back, wrist/hand and shoulder region. Thus, the study reveals that due to the monotonous, repetitive and continuous task performed by the workers, there is an onset of musculoskeletal discomfort (MSD) which may lead to disorders in due course of time which will affect their life.
\end{abstract}

Keywords: Body Discomfort, Glass Industry, Hot Environment, Musculoskeletal Disorder

\section{INTRODUCTION}

A wide-ranged production in glass industries and consequently risks differ both in type and intensity. The risk or the hazards in glass manufacturing industries were chemical hazards, ergonomic hazards, heat stress, physical hazards etc. and these hazards were considered as occupational hazards for the glass industries. According to the report by Shafi (2015) the combination of chemicals, heat and glass used in this industry is a major health hazard for the workers who suffer from various medical disorders.

Manufacturing units of many industries engaged workers in various activities which demands continuous repetitive motions likes lifting lowering, pushing, pulling, carrying, holding, or restraining things which results in awkward postures, occupational fatigue and injuries. According to Anita et al. (2014) the work movements in the manufacturing unit are repetitive in nature and pain in the body

\section{Article Info}

DOI:10.31018/jans.v11i2.2082 Received: April 25, 2019

Revised: May 29, 2019

Accepted: June 2, 2019

\section{How to Cite}

Tewari, S. and Vinay, D. (2019). Musculoskeletal disorders amongst workers of glass manufacturing unit of Western Uttar Pradesh. Journal of Applied and Natural Science, 11(2): 445 - 449 https:/l doi.org/10.31018/ jans.v11i2.2082 
Tewari, S. and Vinay, D. / J. Appl. \& Nat. Sci. 11(2): 445 - 449 (2019)

study that the prevalence of MSDs of the neck, shoulders, hands and wrists were by the workers. Industries, including "Basic Metal Industries" and "Buildings Construction were among the top ten which have high-risk for multiple body parts. The study was conducted keeping in mind the objective of identifying the musculoskeletal disorders in workers engaged in glass manufacturing unit in Uttar Pradesh.

\section{METHODOLOGY}

The sample size chosen for the study was 120 male workers selected randomly engaged from the manufacturing unit of glass industry in western UP. The workers engaged in this section of the factory perform following activities: (i) ball making, (ii) blowing, (iii) mold closing (iv) helping (taking the final product to the other unit or if found defected then crushed. When these activities are carried out, workers most often have to adopt awkward postures along with the exposure to the hot environment that result in musculoskeletal pain/discomfort affecting different body parts. Therefore, OSHA'S (Occupational Safety and Health Administration's) Body mapping exercise was used to assess the physical discomfort faced by workers.

\section{RESULTS AND DISCUSSION}

Body discomfort regions: The workers of the manufacturing unit, while performing blowing, ball making, mold closer and helping task adopts various awkward postures which are monotonous and repetitive in nature and leads to discomfort in body parts. Therefore the workers were asked about the affected regions of their body which lead to discomfort because of their r occupation or activities or the task they perform. The Table1 depicts frequency and \% of the workers showing discomfort in various regions of the body.

It is evident from the table 1 that majority of the blowers felt discomfort in their wrist $(59.46 \%)$ followed by $45.95 \%$ blowers were having discom-

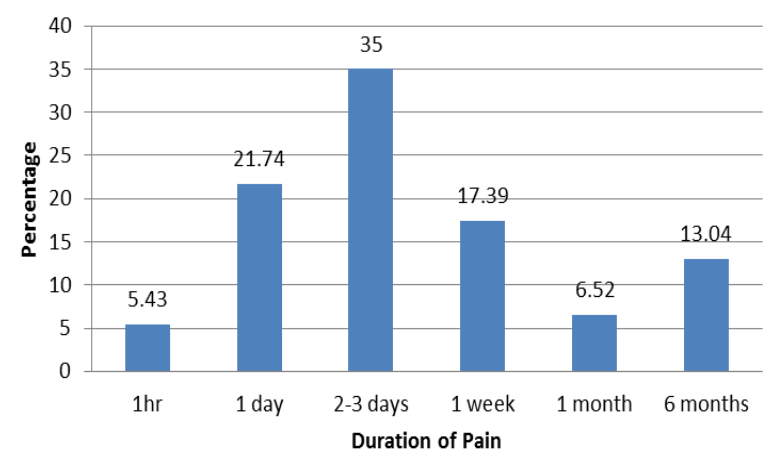

Fig.1. Duration of Pain reported by the workers.

fort in their lower back. The other discomfort body parts reported by the blowers were knee(32.43 \%),Neck (24.32 \%), shoulder (24.32\%), Elbow/ forearm(16.22 \%), ankle/foot (16.22\%) and only $5.14 \%$ and $2.70 \%$ of the blowers have reported discomfort in their upper back and thigh respectively. Some of the blowers(13.51) do not responded to this questions while $18.92 \%$ do not reported any kind of pain or discomfort.

Among ball makers it was observed that discomfort regions were wrist $(50.00 \%)$ followed by discomfort of angle/foot $(23.53 \%)$ and Neck and lower back problem i.e.17.65 \% each. The other discomfort body regions were knee $(11.76 \%)$, shoulder $(5.88 \%)$, thigh $(5.88 \%)$ and Elbow/forearm $(5.88 \%)$ were reported by the ball makers.

It was clearly depicted that among the mold closer workers, maximum of them reported discomfort in their knee $(50.00 \%)$ and upper $\operatorname{back}(42.31 \%)$ followed by discomfort of thigh (34.62 $\%)$,shoulder (30.77\%) and lower back (26.92 \%) and other reported body discomfort parts included ankle/foot (19.23\%), neck (15.38\%), elbow/ fore$\operatorname{arm}(15.38 \%)$ and wrist/hand (3.85\%). Approximately $12 \%$ of the workers engaged in closing of the mold do not respond and nearly $4 \%$ do not reported any kind of discomfort in body regions. Among helpers, it was observed that majority of them were facing discomfort of their lower back

Table1. Distribution of the workers of glass manufacturing unit as per their Body Discomfort Regions.

\begin{tabular}{llllll}
\hline Individual sample & $\begin{array}{l}\text { Blowing } \\
\mathbf{n 1 = 3 7}\end{array}$ & $\begin{array}{l}\text { Ball making } \\
\text { N2=34 }\end{array}$ & $\begin{array}{l}\text { Mold Closer } \\
\text { N3=23 }\end{array}$ & $\begin{array}{l}\text { Helpers } \\
\text { N4=26 }\end{array}$ & $\begin{array}{l}\text { Total } \\
\mathbf{N = 1 2 0}\end{array}$ \\
\cline { 2 - 6 } & $\begin{array}{l}\text { Frequency } \\
(\mathbf{\% )}\end{array}$ & $\begin{array}{l}\text { Frequency } \\
\mathbf{( \% )}\end{array}$ & $\begin{array}{l}\text { Frequency } \\
(\mathbf{\%})\end{array}$ & $\begin{array}{l}\text { Frequency } \\
\mathbf{( \% )}\end{array}$ & $\begin{array}{l}\text { Frequency } \\
(\%)\end{array}$ \\
\hline No response & $5(13.51)$ & $5(14.71)$ & $3(11.54)$ & $1(4.35)$ & $14(11.67)$ \\
No pain & $7(18.92)$ & $0(0.00)$ & $1(3.85)$ & $6(26.09)$ & $14(11.67)$ \\
Neck & $9(24.32)$ & $6(17.65)$ & $4(15.38)$ & $0(0.00)$ & $19(15.83)$ \\
Shoulder & $9(24.32)$ & $2(5.88)$ & $8(30.77)$ & $6(26.09)$ & $25(20.83)$ \\
Upper back & $2(5.14)$ & $1(2.94)$ & $11(42.31)$ & $0(0.00)$ & $14(11.67)$ \\
Elbow/forearm & $6(16.22)$ & $2(5.88)$ & $4(15.38)$ & $6(26.09)$ & $18(15.00)$ \\
Wrist/Hand & $22(59.46)$ & $17(50.00)$ & $1(3.85)$ & $5(21.74)$ & $45(37.50)$ \\
Fingers & $0(0.00)$ & $0(0.00)$ & $0(0.00)$ & $2(8.70)$ & $2(1.67)$ \\
Lower back & $17(45.95)$ & $6(17.65)$ & $7(26.92)$ & $7(30.43)$ & $37(30.83)$ \\
Thigh & $1(2.70)$ & $2(5.88)$ & $9(34.62)$ & $7(30.43)$ & $19(15.83)$ \\
Knee & $12(32.43)$ & $4(11.76)$ & $13(50.00)$ & $4(17.39)$ & $33(27.50)$ \\
Ankle /foot & $6(16.22)$ & $8(23.53)$ & $5(19.23)$ & $4(17.39)$ & $23(19.17)$ \\
\hline \hline
\end{tabular}


Tewari, S. and Vinay, D. / J. Appl. \& Nat. Sci. 11(2): 445 - 449 (2019)

Table 2. Distribution of the workers on the basis of reported symptoms of discomfort.

\begin{tabular}{lllllll}
\hline S.N. & $\begin{array}{l}\text { Symptoms } \\
\text { Pain }\end{array}$ & $\begin{array}{l}\text { of } \\
\text { Blowing }\end{array}$ & $\begin{array}{l}\text { Ball making } \\
\text { (n2=34) }\end{array}$ & $\begin{array}{l}\text { Mold Closer } \\
\text { (n3=26) }\end{array}$ & $\begin{array}{l}\text { Helpers } \\
\text { (n4=23) }\end{array}$ & $\begin{array}{l}\text { Total } \\
\text { (N=120) }\end{array}$ \\
\hline 1. & No response & $5(13.51)$ & $5(14.71)$ & $3(11.54)$ & $1(4.35)$ & $14(11.67)$ \\
2. & No pain & $7(18.92)$ & $0(0.00)$ & $1(3.85)$ & $6(26.09)$ & $14(11.67)$ \\
3. & pain & $16(43.24)$ & $21(61.76)$ & $13(50.00)$ & $13(56.52)$ & $63(52.50)$ \\
4. & burning & $0(0.00)$ & $2(5.88)$ & $0(0.00)$ & $0(0.00)$ & $2(1.67)$ \\
5. & cramping & $3(8.11)$ & $2(5.88)$ & $2(7.69)$ & $4(17.39)$ & $11(9.17)$ \\
6. & numbness & $3(8.11)$ & $2(5.88)$ & $1(3.85)$ & $1(4.35)$ & $7(5.83)$ \\
7. & swelling & $4(10.81)$ & $0(0.00)$ & $2(7.69)$ & $4(17.39)$ & $10(8.33)$ \\
8. & stiffness & $1(2.70)$ & $1(2.94)$ & $0(0.00)$ & $0(0.00)$ & $2(1.67)$ \\
9. & aching & $11(29.73)$ & $4(11.76)$ & $2(7.69)$ & $6(26.09)$ & $23(19.17)$ \\
10. & tingling & $11(29.73)$ & $3(8.82)$ & $6(23.08)$ & $3(13.04)$ & $23(19.17)$ \\
11. & weakness & $4(10.33)$ & $2(5.88)$ & $0(0.00)$ & $1(4.35)$ & $7(5.83)$ \\
\hline
\end{tabular}

and thigh viz. $30.43 \%$, they also reported discomfort of shoulder (26.09\%), elbow/forearm (26.09 $\%)$, hand/wrist $(21.74 \%)$,knee $(17.39 \%)$ and an$\mathrm{kle} /$ foot $(17.39 \%)$ and fingers (8.70 \%). Among helpers approximately $26 \%$ of them do not report pain and $4.35 \%$ do not responded.

In a nut shell it can be concluded that discomfort was found majorly in wrist $(37.50 \%)$, lower back $(30.83 \%)$ and knee $(27.50 \%)$ region. Other prominent discomfort regions were shoulder $(20.83 \%)$ and ankle/foot (19.17\%). The other discomfort body regions were neck (15.83\%), thigh $(15.83 \%)$, elbow /forearm (15.00\%), upper back $(11.67 \%)$ and fingers $(1.67 \%)$. The result was found to be similar to the study of Gangopadhyay et al. (2007) on brass metal workers in which experimental group had a problem of discomfort in their upper extremities, predominantly in the hand $(70 \%)$, wrist $(62 \%)$, fingers $(60 \%)$ and shoulder $(40 \%)$ region. Mean et al. (2013) also reported that male operators working on the laser cutting workstation felt discomfort in metal stamping industry, mostly at the lower back $(52.79 \%)$ along with both forearms $(11.36 \%)$,both wrists $(4.57 \%)$ and both upper arms (3.61\%).

Symptoms of discomfort: After identification of the various discomfort regions of the body, workers were investigated about the symptoms they possess which describe their discomfort. The responses of the blowers revealed that approximately $43 \%$ of the workers have pain, $29.73 \%$ of each have ache and tingling. The other symptoms reported by them are weakness $(10.33 \%)$, swelling $(10.33 \%)$, cramping $(8.11 \%)$ and numbness (8.11\%).

When discussed with the ball makers about the symptoms that describes their discomfort, majority of the workers were having pain $(61.76 \%)$ and other reported symptoms are ache(11.76\%), tingling $(8.22 \%)$ and $5.88 \%$ of the workers reported the symptoms of burning, cramping, numbness, weakness and only $2.94 \%$ reported stiffness.

The table2 also revealed the symptoms reported by mold closers and depicts that $50 \%$ of the workers have pain, $23.08 \%$ have tingling, $7.69 \%$ of the workers have cramps, swelling, ache and only $3.85 \%$ have numbness as a symptom.

When investigated with helpers, here also 56.52 $\%$ of the respondent reported pain followed by ache $(26.09 \%)$, cramps and swelling, tingling, numbness and weakness was found to be reported by $17.39 \%, 13.04 \%$ and $4.35 \%$ of the workers respectively.

In total, more than half of the workers followed by 19.17 workers having ache and tingling. The workers also complain about cramps $(9.17 \%)$, weakness $(5.83 \%)$, numbness $(5.83 \%)$ and only 1.67 $\%$ complains about stiffness while discoloration was not reported by any of the workers.

The results coincided with the study of Gangopadhyay et al. (2007) in which the experimental group of brass metal workers reported pain (80 $\%)$, tingling $(40 \%)$ and numbness $(28 \%)$ of their hands.

Intensity of pain: Intensity of the pain is different for different individual. After identifying the symptoms, it is necessary to ask for the intensity of the discomfort. In conversation with the ball makers it was reported by them that moderate pain was found to be in wrist/hand $(41.18 \%)$, ankle/foot $(23.53 \%)$,knee $(1.76 \%)$, lower back $(8.82 \%)$, neck $(5.88 \%)$, thigh $(5.88 \%)$, upper back $(2.94 \%)$ and forearm(2.94\%), severe pain was reported in neck, lower back, shoulder and forearm by 11.76 $\%, \quad 8.82 \%, 5.88 \%$ and $2.94 \%$ of the workers respectively while noticeable pain was found to be in wrist $(8.82 \%)$ region only.

When asked about level of intensity of pain to the blowers, it was reported that more than half of the blowers who responded were having moderate pain in their wrist/hand, followed by lower back (35.14\%), knee(27.03\%), neck(21.62 \% and $16.22 \%$ of the respondent reported moderate pain in their shoulder and elbow/forearms region, while only $13.51 \%, 5.41 \%$ and $2.70 \%$ of the workers reported moderate pain in their ankle/foot, upper back and thigh region respectively. Severe pain was found to be reported in neck, shoulder, wrist/ hand and lower back by only $2.70 \%$ of the workers. Noticeable pain was reported in lower back $(8.11 \%)$, shoulder $(5.41 \%)$, knee $(5.41)$ and an$\mathrm{kle} / \mathrm{foot}(2.70 \%)$ regions by the workers. 
Tewari, S. and Vinay, D. / J. Appl. \& Nat. Sci. 11(2): 445 - 449 (2019)

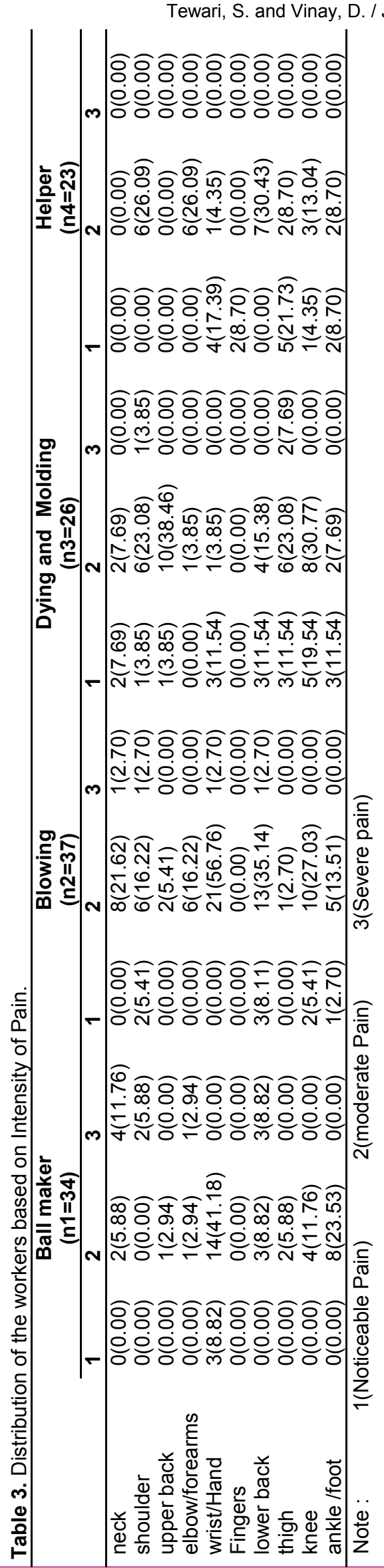

When mold closers were enquired about the intensity of pain, the moderate pain was found to be reported by maximum number of the workers in the upper back(38.46), knee (30.77), shoulder $(23.08 \%)$ and thigh $(23.08 \%)$, severe pain was found to be reported by very few workers in thigh $(7.69 \%)$ and shoulder(3.85 \%) region, while noticeable pain was found to be reported in knee (19.54\%), wrist (11.54\%), lower back (11.54\%), thigh (11.54 \%) and ankle (11.54 \%), neck (7.69\%) and upper back (3.85\%) region.

When asked to helpers about intensity of pain, they reported moderate pain in their in their lower back (30.43\%),shoulders and forearms (26.09\% each), knee (13.04\%), $8.70 \%$ of the respondent reported moderate pain in both of their thigh and ankle/foot. Noticeable pain was found to be reported in thigh $(21.73 \%)$, wrist/ hand $(17.39 \%)$, fingers $(8.70 \%)$, ankle/foot $(8.70 \%)$ and knee(4.35 $\%$ ) region. Summarizing the table 3 about affected area of discomforts, it was found that most affected region reported by ball makers was wrist, blowers reported about wrist, lower back, neck (and shoulder), mold closer reported knee, thigh, upper back and shoulders as their most affect area, helpers reported about were lower back , thigh, forearms and wrist as their most affected region. The results was found to be similar with the study conducted by Hembecker et al. (2017) in metal manufacturing sector workers in which the most frequently affected body region was upper limb which includes shoulder (24.8\%), elbow and/ or forearm (15.5\%), wrist and/or hand (19.0\%).

Duration of discomfort and their likely causes: Pain is the subjective feeling of describing discomfort, it is very important to know the duration of discomfort. When asked about duration of the episode of discomfort maximum number of the workers $(35.85 \%)$ reported $2-3$ days followed by 1 days $(21.74 \%)$. Some of the respondent also reported 1 week $(17.39 \%)$, 6month $(6.52 \%)$ as duration of discomfort and very few (5.43\%) reported 1 hour as duration of discomfort (Fig.1).

The likely causes reported by the workers were twisting or rolling of molten ball, heavy balls, awkward postures, to and fro motion, bending, standing and moving and working in contact with the heat. This shows that the discomfort reported by them were the result of task or activity they performed.

Test statistics: The chi square test was used to assessed the relationship between the task performed by the workers and level of pain or discomfort among different body regions. So, it was found that there is significant difference between task performed and level of pain in neck (21.9 at $1 \%$ and hand/wrist (24.428 at $1 \%)$, shoulder $(13.85$ at $5 \%)$ and lower back(17.015 at $5 \%)$ while no significant difference was found in the thigh and knee region (Table 4). 
Tewari, S. and Vinay, D. / J. Appl. \& Nat. Sci. 11(2): 445 - 449 (2019)

Table 4. Chi square values for finding relationship between the task performed by the workers and level of pain or discomfort among different body regions.

\begin{tabular}{llll}
\hline Task performed & Body Regions & Chi Square & Significance level \\
\hline & Neck & $21.9^{\star *}$ & Significant at $1 \%$ \\
Ball maker & Shoulder & $13.85^{*}$ & Significant at $5 \%$ \\
Blower & Wrist/Hand & $24.428^{* *}$ & Significant at $1 \%$ \\
Mold Closer & Lower Back & $17.015^{*}$ & Significant at $5 \%$ \\
Helper & Thigh & 7.407 & Non Significant \\
& knee & 4.009 & Non Significant \\
\hline
\end{tabular}

\section{Conclusion}

The problem in the wrist was observed to be more prominent among blowers (59.46\%) followed by ball makers $(50.00 \%)$ in glass manufacturing unit. While problem of lower back was found to be more common among blowers (45.95\%) and mold closers $(26.92 \%)$ and helpers i.e. $30.43 \%$. Relationship between task performed and the level of discomfort was found to be significant in neck, lower back, wrist/hand and shoulder region while no significance difference was found in thigh and knee region. The likely causes reported by the workers showed that they are occupational hazards.As reported, cause of the discomfort was related to their task which they performed. Thus, the study revealed that there is an onset of musculoskeletal discomfort which may lead to disorders in due course of time which will affect their life.

\section{ACKNOWLEDGEMENTS}

The author would like to acknowledge UGC for funding the above mentioned work of Ph.D. degree programme through NET-JRF Fellowship and the Department of Family Resource Management, College of Home Science, G.B. Pant University of Agriculture and Technology, Pantnagar for generating insight in context of the research problem. The author would also like to acknowledge Glass Industry Unit for granting permission to conduct the study considering the ethical concerns of the industry.

\section{REFERENCES}

1. Anita, A. R., Yazdani, A., Hayati, K. S. and Adon, M. Y. (2014). Association between Awkward Posture and Musculoskeletal Disorders (MSD) among Assembly Line Workers in an Automotive Industry. Ma- laysian Journal of Medicine and Health Sciences, 10 (1): 23-28ISSN 1675-8544

2. Gangopadhyay,S., Ghosh,T., Das,T. , Ghoshal, G. And Das,B.B. Prevalence of Upper Limb Musculo Skeletal Disorders among Brass Metal Workers in West Bengal, India . Industrial Health 2007, 45, 365370

3. Guo, H.R., Chang, Y.C., Yeh, W.Y., Chen, C.W., Guo, Y. L. (2004). Prevalence of musculoskeletal disorder among workers in Taiwan: a nationwide study.Journal of Occupational Health, 46(1):2636.doi: $\quad$ https://doi.org/http://doi.org/10.1539/ joh.46.26.

4. Hembecker, P. K., C Reis, D., Konrath, A. C., A Gontijo, L., \& D Merino, E. A. (2017). Investigation of musculoskeletal symptoms in a manufacturing company in Brazil: a cross-sectional study. Brazilian Journal of Physical Therapy, 21(3): 175-183. doi:10.1016/j.bjpt.2017.03.014

5. Mean, V., Abdullah N. S. M., Dawal, S. Z., Aoyama H. (2013). Investigation on Musculoskeletal Symptoms and Ergonomic Risk Factors at Metal Stamping Industry. Advanced Engineering Forum. 10: 293-299. https://doi.org/10.4028/www.scientific.net/AEF.10.293

6. Queiróz, M. de F. F., \& Maciel, R. H. (2000). A Comparative Study of Work Places in Two Glass Industries: An Automated and a Manual One. Proceedings of the Human Factors andErgonomics Society Annual Meeting, 44(29): 193196. https://doi. or g /10.1177/154193120004402951

7. Roquelaure $Y^{1}$, Ha C, Nicolas G, Pélier-Cady MC, Mariot C, Descatha A, Leclerc A, Raimbeau G, Goldberg M, Imbernon E. (2008). Attributable risk of carpal tunnel syndrome according to industry and occupation in a general population. Arthritis Rheum, 59: 1341-1348. https://www.hal.inserm.fr/file/index/ docid/327497/filename/inserm-00327497_edited.pdf

8. Shafi, S. (2015). Indian town where glass-making is a household craft. Retrieved from https:// www.aljazeera.com/indepth/inpictures/2015/02/indian -town-glass-making-household-craft150209200924438.html 